\title{
O Último PÉ E A CESURA NOS VERSOS NúNICOS E AS PÚNICAS DE SÍLIO ITÁLICO
}

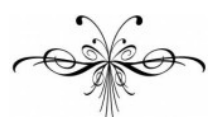

\section{EVERTON NATIVIDADE}

Resumo: Este artigo apresenta as possibilidades de formação do último pé e as ocorrências de cesuras nos chamados versos núnicos, uma transposição do hexâmetro datílico latino utilizada por Carlos Alberto Nunes nas suas traduções de Homero e Virgílio, após retomar as características desse mesmo verso, conforme apresentadas em estudos anteriores. Em apêndice, oferece-se uma tradução de um excerto das Púnicas de Sílio Itálico (6.589-659), em versos núnicos, com escansão e notas de comentário.

Palavras-chave: Versos núnicos; último pé; cesura; tradução; Sílio Itálico.

\begin{abstract}
This paper presents the possibilities of forming the last foot and the occurrences of caesuras in the so called "nunean verses", a transposition of Latin dactylic hexameter used by Carlos Alberto Nunes in his translations of Homer and Virgil, after summarizing the characteristics of that same verse, as presented in previous papers. In appendix, we offer a translation of an excerpt from Silius Italicus' Punica (6.589-659), in "nunean verses", with scansion and commentary notes.
\end{abstract}

Keywords: Nunean verses; last foot; caesura; translation; Silius Italicus.

La cour que constituaient les écoutants était leur arène ; souvent, ils s'affrontaient avec cette arme immatérielle, toute pure, aérienne et tranchante qu'était la Parole.

Patrick Chamoiseau, in Biblique des derniers gestes

$\mathrm{R}$ evalorizar os clássicos e algumas de suas traduções parece ser um movimento cíclico, que se poderia alegar que espelha, de certa forma, a tendência de leitura e leitores das épocas em que cada revalorização se lobriga. Assim é que entre os tradutores mais conhecidos e citados da Eneida, por exemplo, Manuel Odorico Mendes e Barreto Feio, será 
possível encontrar Carlos Alberto Nunes, cuja paulatina reimpressão ${ }^{1}$ indica um momento de merecida revisitação. Ao lado dessas reimpressões, um estudo analítico e de "instauração de uma tradição", no que tange ao método de tradução poética de Carlos Alberto Nunes, vem sendo empreendido por um grupo da Universidade Federal do Paraná. Dois textos já se publicaram como fruto desse trabalho: (1) Conto (2008), um estudo das técnicas empregadas pelo poetatradutor, com um esboço de interpretação de intenções distintas que se podem depreender nas traduções dele e de Odorico Mendes; e (2) Gonçalves et alii (2011), que retoma os resultados já apresentados por Conto e se faz acompanhar de uma tradução do canto X dAs Metamorfoses de Ovídio.

Desses estudos, depreende-se a prática de Carlos Alberto Nunes, que, oferecendo ao português uma tradução peculiar do hexâmetro datílico grecolatino, propôs, grosso modo, um verso de número de sílabas variável, composto de cinco combinações da sequência tônica-átona-átona (doravante TAA) e uma, final, de TAA ou tônica-átona (TA) ou, ainda que raramente, de uma só sílaba tônica ${ }^{2}$. Essa invenção do poeta-tradutor, já denominada de "transposição do hexâmetro datílico antigo por um hexâmetro datílico equivalente português”3, "hexâmetro vernáculo"4 e mesmo "verso núnico" (e é esta última denominação que passaremos a adotar), acabou por ganhar uma série de características próprias que se resumem em seis pontos:

1. À sílaba longa do início de cada pé (dátilo, espondeu ou troqueu) do hexâmetro datílico corresponde, em português, uma sílaba tônica, mantendo-se o icto de cada pé do verso greco-latino;

2. Às sílabas breves (segunda e terceira do dátilo; segunda do troqueu) correspondem, em português, sílabas átonas;

3. Ao primeiro dátilo de cada hexâmetro corresponderá, em português, um sequência TAA ou ATA $^{6}$ ou, ainda, na possibilidade de uma anacruse ${ }^{7}$, ATAA;

4. Não haverá, nos cinco primeiros pés do verso vernáculo, a possibilidade de substituição de um dátilo por um espondeu; por conseguinte, o verso núnico se comporá de cinco sequências TAA, seguida da sexta e última;

5. O último pé do verso núnico poderá compor-se de uma sequência TAA (equivalente do dátilo) ou TA (equivalente do troqueu) ou, ainda, de uma só sílaba tônica (verso encerrado por uma oxítona);

6. Como consequência dos itens 4. e 5. acima exarados, o verso núnico se comporá de 16-18 sílabas, diferentemente do hexâmetro datílico original, composto de 13-17 sílabas. ${ }^{8}$

\footnotetext{
${ }^{1}$ Para a Eneida, cf. VIRGílLIO, 1981. Para as reimpressões, todas dos poemas homéricos, cf. HOMERO, 2009a e 2009b (ambas da Ediouro, comercializadas em box especial); 2011a, 2011b, 2011c, 2011d.

${ }^{2}$ Segundo GONÇALVES et al. (2011, p. 8).

${ }^{3}$ GONÇALVES et al., 2011, p. 3.

${ }^{4}$ GONÇALVES et al., 2011, p. 3, n. 5.

${ }^{5}$ CONTO, 2008, p. 60, n. 1.

${ }^{6}$ Com o "recurso da inversão de sílaba tônica”, como o denomina Conto (2008, p. 63).

${ }^{7}$ Gonçalves et al., 2011, p. 8, define-nos o termo de forma simples e clara: "é a sílaba ou sílabas que antecedem a tônica inicial de um verso e não são consideradas na escansão”.

${ }^{8} \mathrm{O}$ esquema gráfico abaixo facilita a visualização das possibilidades de construção de um verso núnico. Cada letra indica uma sílaba ( $\mathrm{T}=$ tônica, em fonte maior e em negrito; $\mathrm{A}$ = átona); cada conjunto de sílabas (pé) está separado do seu subsequente num quadro; as sílabas tônicas, icto em cada pé, marcam-se com o negrito e em fonte maior:
} 
Essas as características essenciais, cujos pequenos detalhes foram minuciosamente estudados nos dois trabalhos a que nos referimos. Conto ${ }^{9}$, no entanto, assinala que "ainda faltou [...] a abordagem de questões como a cesura do hexâmetro latino e a sílaba final do verso de Nunes”. O problema da sílaba final, como veremos a seguir, seria, três anos depois, tangencialmente abordado no texto de Gonçalves. Quanto à cesura, apresentamos, neste estudo, o resultado da nossa pesquisa, que se deteve justamente sobre esta questão. A exemplo da produção de Gonçalves e seu grupo, concluímos este texto com a tradução, em apêndice, de uma passagem das Púnicas de Sílio Itálico (6.589-659), elaborada no verso núnico, com observação dos parâmetros de cesura que aqui se apresentam. Um segundo apêndice reapresenta o texto da tradução com as cesuras e ictos marcados; o terceiro e último traz notas e comentários.

\section{O último pé do verso núnico}

O hexâmetro datílico, composto da combinação de seis pés, podia ter, entre os quatro primeiros ou em todos esses quatro iniciais, o dátilo substituído por um espondeu; ao quinto pé cabia a manutenção do ritmo, o que lhe obrigava a conservação de um dátilo; o último pé do verso, enfim, constituía-se ou de um troqueu ou de um espondeu. A transposição dessa forma fixa para o português fez que

Carlos Alberto teve que fixá-lo com cinco pés dátilos e sexto pé quase sempre trocaico, raramente dátilo, pois [...] não se consegue utilizar espondeu em português, e a única possibilidade de variar que restou ao tradutor foi substituir o troqueu final por um dátilo, ou em outras palavras, usar verso grave ou verso esdrúxulo ${ }^{10}$.

Como sói acontecer no tipo de trabalho que empreenderam Conto e Gonçalves - e neste por que ora enveredamos - os termos utilizados na métrica latina e na versificação portuguesa se confundem. Assim é que, em referência às combinações de sílabas do verso núnico, usa-se o termo "pés”, o pé formado de TAA chama-se dátilo; o de TA, trocaico; o de TT, espondeu. Nessa confluência de terminologias, uma impropriedade foi cometida: chama-se rima grave à que faz identificarem-se palavras paroxítonas e esdrúxula à que faz identificarem-se palavras proparoxítonas. Os termos, empregados na versificação portuguesa com referência a tipos de rimas $^{11}$ (ou terminações ${ }^{12}$ ), então, foram retomados por Gonçalves, na citação acima, como classificação possível para o verso. Postos à parte esses detalhes, compreende-se logo que Gonçalves, ao elencar as possibilidades a que tinha acesso Carlos Alberto Nunes para a confec-

\begin{tabular}{|l|l|l|l|l|l|}
\hline TAA & & & & & TAA \\
ATA & TAA & TAA & TAA & TAA & $\begin{array}{l}\text { TA } \\
\text { TTA }\end{array}$ \\
\hline
\end{tabular}

${ }^{9}$ 2008, p. 66.

${ }^{10}$ GONÇALVES et alii, 2011, p. 8.

${ }^{11}$ Cf. CHOCIAY, 1974, p. 176.

${ }^{12}$ Cf. CHOCIAY, 1974, pp. 34 e 43. 
ção do seu sexto pé, chega à conclusão de que eram duas: TA ou, raramente, TAA.

Um pouco antes, no mesmo artigo ${ }^{13}$, Gonçalves havia afirmado, no entanto, que "o hexâmetro vernáculo de Carlos Alberto Nunes pode apenas ter entre 16 e 18 sílabas, conforme o último pé seja troqueu, dátilo ou mesmo oxítona, como se exemplificará a seguir" (grifo nosso). É somente a partir de um exemplo extraído da tradução apresentada pelo grupo ${ }^{14}$, que compreendemos o que se entende por "oxítona”: o sexto pé formado por uma só sílaba, tônica:

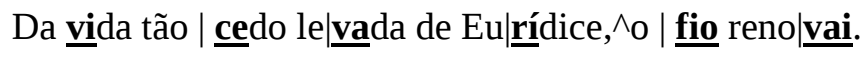

Com efeito, ainda que muito raramente, encontra-se, entre os versos núnicos, o pé final formado de uma só sílaba tônica, o que implica, evidentemente, um verso terminado em oxítona. Nos 1.558 versos que formam a tradução dos cantos I e II da Eneida, há somente três ocorrências, todas originárias do emprego de um nome próprio oxítono: “Menão” (1.489); "Heitor” (1.755) e "Peneleu” (2.424).

Menos rara é a terminação em proparoxítona, que cria um pé final datílico (TAA). Nos mesmos 1.558 versos, encontram-se 12 ocorrências, das quais quatro se formam do nome "Príamo" (2.436, 452, 505 e 759); duas vezes ocorre "Hípanis" (2.339 e 427); as outras seis ocorrências, uma vez para cada palavra, incluem um só adjetivo ("riquíssimo", 2.391) — as outras todas são, previsivelmente, nomes próprios ("Deífobo", 2.309; "Migdônida”, 2.340; “Ífito”, com a primeira vogal em elisão com a final do verbo "era”, 2.434; "Pérgamo", 2.554; "Górgona”, 2.615). Note-se ainda que a terminação esdrúxula parece ter sido evitada, se considerarmos as proparoxítonas sincopadas em 1.225 (“espetac’lo"), 1.291 (“sec’los”) e 1.653 (“per’las”).

\section{A cesura no verso núnico}

A cesura, definida como "uma pausa que divida um pé, metro ou cólon” ${ }^{15}$, ocorre no verso hexâmetro datílico, no mais das vezes, após a longa do terceiro pé, quando é, então, chamada pentemímera. Há ainda as cesuras triemímera, que ocorre após a longa do segundo pé, e heftemímera, que ocorre após a longa do quarto pé. Uma cesura que se dá após a primeira breve do terceiro pé chama-se feminina.

Essas quatro possibilidades de cesura podem encontrar-se em combinações, dando ao verso duas ou três pausas. A heftemímera muito frequentemente se combina com a pentemímera ou com a triemímera; podem-se também combinar as três, a um tempo, criando-se um verso dividido em quatro partes. A cesura feminina pode, igualmente, vir combinada com uma heftemímera ou com triemímera e heftemímera no mesmo verso.

\footnotetext{
${ }^{13}$ GONÇALVES et alii, 2011, pp. 4-5.

${ }^{14}$ GONÇALVES et alii, 2011, p. 9. O verso é o 10.31 dAs Metamorfoses. Nos exemplos deste artigo, as barras verticais indicam a separação entre os pés, as diagonais paralelas a cesura (não marcada no exemplo em questão); as sílabas tônicas (ou o icto, equivalente à longa do pé latino) de cada pé encontram-se em negrita e sublinhadas, e as sinalefas, elisões e ectlipses indicam-se por um acento circunflexo entre as vogais (ou os grupos) que se reúnem.

${ }^{15}$ CRUSIUS, 1951, p. 43 (§ 36).
} 
A breve exposição dos parágrafos anteriores deve servir-nos a compreender a cesura no verso núnico, que, esperaríamos, reproduz, rspeitando as exigências do português, as possibilidades do latim. Não seria de somenos correção supor, em vista da já exposta limitação do português diante da expressividade do hexâmetro latino, que, também com relação às cesuras e suas combinações, o português (ou o modelo núnico, neste caso) oferecesse reduções. Com efeito, Carlos Alberto Nunes, num dos poucos excertos que conhecemos em que se refira à construção dos versos de transposição do hexâmetro datílico, oferece-nos a seguinte preceituação:

[...] discreta cesura depois do terceiro pé:

Ouve-me, Atena, também, / nobre filha de Zeus poderoso!

Quando o poeta se afasta desse paradigma, para introduzir duas pausas no verso, que o dividem em três porções quase iguais, de regra volta no verso subsequente a cair no ritmo inicial, que é o predominante em todo o recitativo:

Dá que possamos / cobertos de glória / voltar para as naves, pós grande feito acabarmos / que há de lembrar sempre os Teucros!

Nas traduções esse esquema não é observado com rigor, notando-se, ainda, a tendência para variar de ritmo, pelo deslocamento das pausas dentro do verso, com o que se evita a monotonia, de possível desagrado para o ouvido moderno ${ }^{16}$.

Nessa citação, convém observar que Nunes cita os versos em tradução sua como se fossem os próprios originais do poeta (en l'occurrence, Homero). Vale também notar que ele acentua certa "tendência para variar de ritmo" por parte do tradutor. Se tomarmos ao pé da letra a preceituação, reduzir-se-ia a cesura nos versos núnicos a duas possibilidades somente: as equivalentes da pentemímera e da combinação de triemímera com heftemímera. Não é isso, contudo, que se vê nos dados que temos analisado ${ }^{17}$. A seguir, por meio de exemplos tomados ao corpus, exporemos notícia das possibilidades de cesura no verso núnico, encerrando com um breve elenco das características que se detectaram.

A ocorrência mais frequente é a da cesura pentemímera só; ela aparece em 57 versos do corpus em tradução ${ }^{18}$. É seguida, em quantidade, pela heftemímera desacompanhada, que se vê em 14 versos ${ }^{19}$. A combinação de triemímera com heftemímera se conta em $11 \operatorname{casos}^{20}$. A triemímera desacompanhada se

\footnotetext{
${ }^{16}$ NUNES, 1962, p. 39.

${ }^{17} \mathrm{O}$ corpus deste trabalho se compôs dos cem versos iniciais do primeiro canto da Eneida, cujos original latino e tradução foram escandidos e comparados.

${ }^{18}$ Pentemímera propriamente dita: versos 1, 5, 6, 10-12, 19, 38, 42, 43, 45, 52, 60, 66, 76, 79, 84, 89, 94, 99; cesura feminina: versos 2, 3, 7, 8, 13-15, 24-32, 40, 50, 53, 56, 57, 61, 64, 68, 69, $71,72,74,78,80,85,86,88,91,96,97,100$. Na prática, a utilização da cesura que faz Carlos Alberto Nunes, não há diferença marcada entre a pausa colocada entre a longa e a primeira breve do dátilo (T // AA) ou entre a primeira breve e a segunda (TA // A); desfaz-se, assim, no esquema de cesuras possíveis, a distinção entre cesura pentemímera e cesura feminina. Por isso, referimo-nos a ambas pelo termo comum de pentemímera, quando em referência às suas ocorrências nos versos núnicos.

19 São eles: 16, 18, 21-23, 33, 34, 51, 55, 62, 67, 73, 87 e 95.

20 São eles: versos $9,17,20,26,35,44,46,48,49,63$ e 82.
} 
vê em 10 exemplos, os versos 36, 37, 39, 41, 54, 58, 65, 75, 93 e 98; o oitavo deles (75), traduz um verso de cesura pentemímera:

exigat, | $\underline{\text { et }}$ pul|chra $/ /$ faci|at te | prole pa|rentem

e pai te | tornes // de | prole sa| $\underline{\text { dia }}{ }^{\wedge} \mathrm{e}^{\wedge}$ inve|jada de $\mid \underline{\text { to }} \operatorname{dos}^{21}$

Curiosamente, em uma ocorrência da cesura triemímera no original, equivale uma pentemímera na tradução, verso 61:

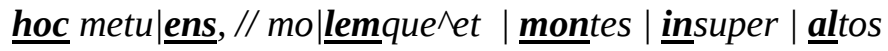

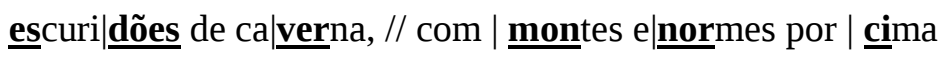

Com os exemplos anteriores, observamos que, na "tendência para variar de ritmo" do poema traduzido, as cesuras da Eneida de Carlos Alberto Nunes nem sempre equivalem, verso a verso, às da virgiliana original ${ }^{22}$. Nem tampouco em termos de técnica: um exemplo recorrente se dá quando, ao passo que as cesuras do hexâmetro latino se encontram quase sempre após a longa do pé em que caem, isto é, após a arse ${ }^{23}$, as cesuras do verso núnico podem — e isso se dá com enorme frequência, reiteremos - cair após a primeira átona do pé, que equivaleria à primeira breve dum pé latino e, no caso da cesura no terceiro pé, não a uma pentemímera, mas a uma feminina, como exemplifica o verso abaixo, o segundo do primeiro canto:

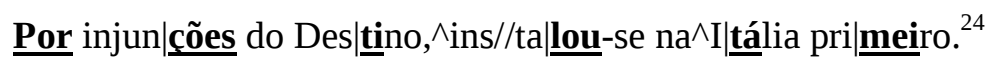

É digno de nota que o tradutor tenha-se servido de quantos recursos encontrou disponíveis, atentando mesmo para práticas que não eram de todo virgilianas, mas encontradiças em autores anteriores, como Lucrécio, caso da diére$\mathrm{se}^{25}$ ao fim do segundo pé, combinada com uma cesura heftemímera ${ }^{26}$, que se exemplifica no verso $47^{27}$ :

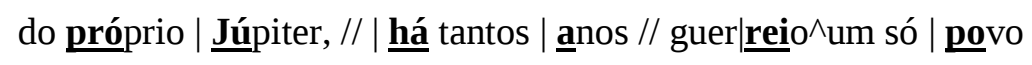

Outro ponto a notar é a possibilidade — não diferentemente do que ocorre, vez ou outra, nos hexâmetros latinos — de interpretação, podendo um

\footnotetext{
${ }^{21}$ Cf. n. 14.

${ }^{22}$ Como, aliás, nem sempre se equivalem palavra por palavra o original latino e a tradução em português.

${ }^{23}$ Chama-se arse à elevação, ao realce silábico existente em cada pé (e, a crer na tese da leitura rítmica marcada pela intensidade também em latim, esse realce será, como em português, acentual); a posição de arse, em latim, é majoritariamente ocupada por uma sílaba longa (cf. CRUSIUS, 1951, p. 39, § 32).

${ }^{24}$ Sobre esse tipo de cesura, a que apresentamos nesse verso, no interior de um vocábulo, “divisão meramente teórica”, cf. CHOCIAY, 1974, p. 127, item 7.15.3.

${ }^{25}$ Chama-se diérese à cesura que coincide com o fim de um pé ou metro (CRUSIUS, 1951, pp. 42-3, § 36).

${ }^{26}$ CRUSIUS, 1951, p. 58 (§ 45.7).

${ }^{27} \mathrm{Na}$ Eneida virgiliana, no corpus analisado, tal cesura se encontra uma vez, no v. 82.
} 
verso ser lido de mais de uma maneira, no que tange à pausa da cesura ${ }^{28}$. O verso 4, por exemplo, poder-se-ia ler

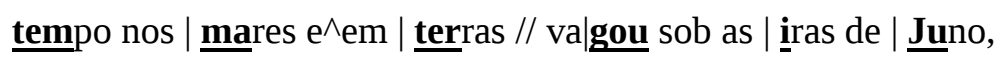

com a cesura pentemímera marcada entre o verbo e o seu adjunto adverbial de lugar, ou com a cesura heftemímera, destacando o adjunto adverbial de causa, como, aliás, o faz o verso original latino, que tem cesura dupla:

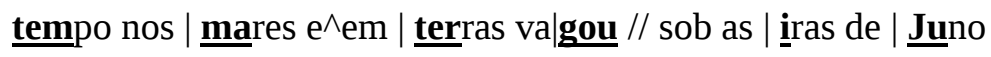

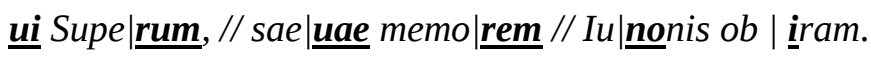

É graças a essa possibilidade de interpretação que poderíamos crer que há, entre os cem versos do corpus, um que retoma a rara cesura tripla, exemplificada com o verso 2.3 da Eneida virgiliana,

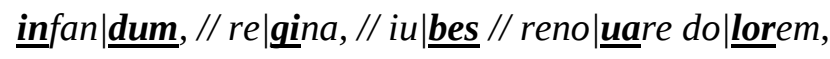

que apresenta triemímera, pentemímera e heftemímera em conjunto no mesmo verso $^{29}$. O exemplo núnico está no verso 77 , em que três leituras nos parecem possíveis. A primeira, com uma só cesura, triemímera:

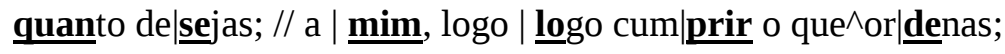

a segunda, com duas cesuras, combinando triemímera com heftemímera:

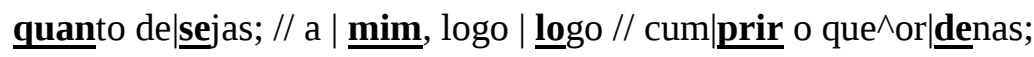

a terceira, com três cesuras, combinando triemímera, pentemímera e heftemímera:

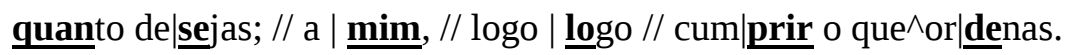

Em resumo, (1) encontram-se nos versos núnicos todas as possibilidades que se possam elencar de cesuras próprias ao hexâmetro épico latino, incluindo-se nesse rol tanto as cesuras únicas quanto as combinações, duplas e triplas; (2) não faz o tradutor distinção quanto à posição da cesura entre a tônica e a átona do início do dátilo ou entre as duas átonas, o que desfaz, por exemplo, a diferença entre a cesura pentemímera e a feminina; (3) as cesuras da tradução não equivalem verso a verso às cesuras do original latino; (4) a possibilidade de interpretação cria diferentes leituras para um mesmo verso, com a pausa da cesura marcada em diferentes lugares.

\footnotetext{
${ }^{28}$ Além do exemplo com que trabalhamos na sequência, o verso 4, possibilidades de leitura foram identificadas nos seguintes versos: 59, 81, 90 (cesura triemímera ou triemímera com heftemímera); 70 (heftemímera ou triemímera com heftemímera); 83 (triemímera ou triemímera com pentemímera); 92 (triemímera ou pentemímera).

${ }^{29}$ O exemplo é dado por Crusius, 1951, p. 60, § 46.
} 


\title{
APÊNDICE 1: Tradução de Sílio Itálico, Púnicas 6.589-659
}

\author{
At cladis acerbae \\ 590 discussa ceu nube, patres conquirere fessis \\ iam rebus meditantur opem, atque ad munera belli \\ certatur, pulsusque timor grauiore periclo. \\ Maxima curarum, rectorem ponere castris, \\ cui Latium et moles rerum quassata recumbat, \\ 595 spectante occasum patria. Iouis illa ruenti \\ Ausoniae atque Italis tempus protendere regnis \\ cura fuit; nam Tyrrhenos Poenumque secundis \\ Albana surgens respexerat arce tumentem, \\ qui ferre in muros uictricia signa parabat.
}

600 Tum quassans caput: "Haud umquam tibi Iupiter", inquit, "o iuuenis, dederit portas transcendere Romae atque inferre pedem. Tyrrhenas sternere ualles caedibus, et ripas fluuiorum exire Latino sanguine fas fuerit: Tarpeium accedere collem 605 murisque aspirare ueto.” Quater inde coruscum contorsit dextra fulmen, quo tota reluxit Maeonidum tellus, atramque per aethera uoluens abrupto fregit caelo super agmina nubem.

Nec Poenum auertisse satis; dat numine magno $\mathbf{6 1 0}$ Aeneadis mentem, gremio deponere tuto Romuleam sedem Fabioque salutis habenas credere ductori. Cui postquam tradita belli iura uidet: "Non hunc", inquit, "superauerit unquam inuidia aut blando popularis gloria fuco; 615 non astus fallax, non praeda aliusue cupido. Bellandi uetus ac laudum cladumque quieta mente capax; par ingenium castrisque togaeque.” Sic genitor diuum, recipitque ad sidera gressum.

Hic, circumspectis nulli deprensus in armis 620 laudatusque Ioui, Fabius mirabile quantum gaudebat reducem patriae annumerare reuersus, duxerat egrediens quam secum in proelia, pubem. Nec membris quisquam natoue pepercit amato acrius, aut uidit socium per bella cruorem 625 tristior. Atque idem, perfusus sanguine uictor hostili, plenis repetebat moenia castris. Stirpe genus clarum caeloque affinis origo. Nam remeans longis olim Tirynthius oris et triplicis monstri famam et spectacula captas 630 mira boues hac, qua fulgent nunc moenia Romae, egit ouans. Tunc Arcadius (sic fama) locabat inter desertos fundata Palatia dumos paupere sub populo ductor, cum regia uirgo, hospite uicta sacro, Fabium de crimine laeto 635 procreat et magni commiscet seminis ortus Arcas in Herculeos mater uentura nepotes. Ter centum domus haec Fabios armauit in hostem, limine progressos uno; pulcherrima quorum 
cunctando Fabius superauit facta ducemque

640 Hannibalem aequando. Tantus tunc, Poene, fuisti!

Dum se perculsi renouant in bella Latini, turbatus Ioue et exuta spe moenia Romae pulsandi, colles Vmbros atque arua petebat Hannibal, excelso summi qua uertice montis 645 deuexum lateri pendet Tuder, atque ubi latis proiecta in campis nebulas exhalat inertes, et sedet ingentem pascens Meuania taurum, dona Ioui; tum Palladios se fundit in agros Picenum diues praedae atque errantibus armis, 650 quo spolia inuitant, transfert populantia signa; donec pestiferos mitis Campania cursus tardauit bellumque sinu indefensa recepit.

Hic dum stagnosi spectat templumque domosque Literni ductor, uaria splendentia cernit 655 pictura belli patribus monumenta prioris exhausti — nam porticibus signata manebant quis inerat longus rerum et spectabilis ordo. Primus bella truci suadebat Regulus ore, bella neganda, uiro si noscere fata daretur.

De acerba procela,

590 fendida a nuvem, os pais a buscar os recursos se empenham para tão grandes trabalhos, e pelos labores da guerra todos disputam, vencido o temor de um perigo maior. Às tropas chefe propor, dos cuidados o máximo, entre forças caídas em quem apoiarem o Lácio abatido, 595 vendo da pátria o ocaso. Mas grande de Jove o cuidado ao reino itálico foi aumentar e à Ausônia a existência já em ruínas, e olhou, da montanha Albana, do topo, o púnico cheio de si e co'ele os tirrenos, soberba!, queria aos muros levar as insígnias das suas vitórias.

600 Abana o deus a cabeça: "Mas Júpiter nunca, meu jovem” diz - "te dará que as portas de Roma transponhas, aí nem pores o pé. As planícies tirrenas com morte arrasaste, foi permitido; e as margens dos rios transbordar com o sangue latino, sim, permiti. Alcançares o monte tarpeio, 605 dos muros te aproximares, proíbo”. E então, coruscantes, lançou coa destra dois pares de raios, e co'eles da Etrúria iluminou-se a região; e nos ares revolve uma escura nuvem, irrompe no céu, que por sobre o exército abriu-se. Ter afastado o fenício não é suficiente; inspira, $\mathbf{6 1 0}$ com grande nume, os Enéadas: ponham as terras romúleas salvas nas mãos condutoras de Fábio, confiem as rédeas pátrias. E assim que ele vê os comandos da guerra rendidos a Fábio, afirma então: “O renome que junto ao povo se faz, coa inveja e o logro falaz, nem astúcia ou ganho, 615 cobiça, nada consegue a este enganar. Aguerrido, recebe os louros na paz e suporta das guerras as perdas, o espírito calmo, de engenho igual para as armas e a toga”. 
Dos deuses falou o supremo; regressa em seguida às estrelas. Aquele, surpreso jamais por ninguém em suas armas prudentes, 620 é estimado de Jove; e Fábio exultava, regresso, por numerar-se de volta, à pátria restituída, a juventude levada consigo p'ra tantos combates. Ninguém salvou-se a si mesmo ou filho querido com zelo maior, ou viu companheiro na guerra a sangrar com tristeza 625 maior. Agora ele mesmo, banhado em cruor inimigo, venceu, aos muros tornava com seus numerosos soldados. Raça de estirpe preclara, ao céu sua origem remonta. Pois, retornando o Tiríntio outrora de terras longínquas, do monstro tríplice arrasta a fama e as vacas tomadas, 630 triunfo, espetáculo, onde refulgem agora as muralhas de Roma. Um árcade, então, como dizem, estabelecia do Palatino as bases por entre desertos silvados; um pobre povo conduz, quando a virgem princesa enleada, do hóspede sacro vencida, de um crime feliz, primo Fábio 635 gera e mistura as origens de nobres sementes, fazendo-se arcádia madre futura, de heráclidas antepassada.

Fábios trezentos armou essa raça de encontro ao imigo, todos saídos de igual limiar; os belíssimos feitos deles, contemporizando, supera este Fábio, que sabe 640 com Aníbal chefe igualar-se. Tão grande, ó púnico, foste! Enquanto à guerra retornam os sobressaltados latinos, amedrontado por Jove e perdida a fé de os romanos muros destruir, às colinas e aos campos da Úmbria alcança Aníbal, onde, no cume elevado do topo de um monte, 645 pende, inclinado, a um lado, o Túder, e onde, estendida em vastos campos, exala inertes neblinas espessas e se situa a Mevânia, pastora de touros enormes, dons para Jove; se lança em seguida nos campos de Palas, Piceno, rico em despojos; vagando, os exércitos seguem 650 aonde os convidam espólios, transportam insígnias pilhadas; até que a doce Campânia as marchas funestas deteve e recebeu, sem defesa, a guerra em seu seio. E nesse lugar, enquanto contempla moradas e templo em Literno cercada de água, Aníbal percebe, de várias cores 655 vivas pintada, a imagem da guerra primeira, a cabo levada pelos seus antepassados, pois marcas restavam, longa seqüência dos fatos gravava-se bela nos pórticos. Primeiro Régulo à guerra, com rosto feroz, exortava, guerra que, dado lhe fosse os fados prever, negaria. 


\section{APÊNDICE 2: Escansão dos versos da tradução apresentada}

Marcam-se, nesta escansão, todas as cesuras que vimos possíveis; em alguns casos, como no v. 606, por exemplo, uma só (a heftemímera) poderia manter-se, desprezando-se a primeira (triemímera) e lendo-se, então, um verso bimembre. Também aqui a possibilidade de interpretação de leitura a que nos referimos nas páginas 7 e 8 deste artigo (exemplificada com os versos 1.4 e 1.77 da Eneida núnica) se mantém. Outros comentários que julgamos pertinentes encontram-se no apêndice 3, em notas.

$\mathrm{De}^{\wedge} \mathrm{a} \mid \underline{\text { cerba pro|cela, }}$

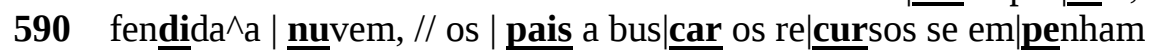
para tão | grandes tra|balhos, // e | pelos la|bores da | guerra

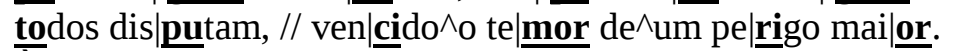

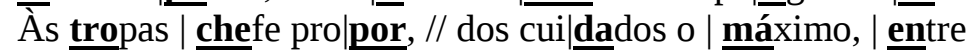

forças calídas // em | quem apoi|arem // o | $\underline{\text { Lácio }} \wedge$ aba|tido,

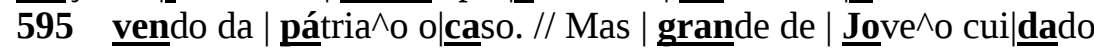

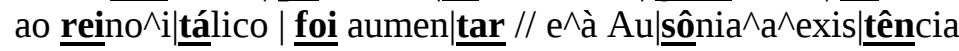

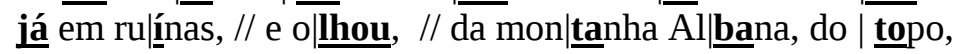

o púnico $\mid$ cheio de $\mid \underline{\mathbf{s i}} / /$ e com | ele $^{\wedge}$ os tir|renos, so|berba!,

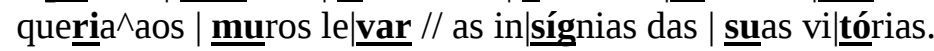

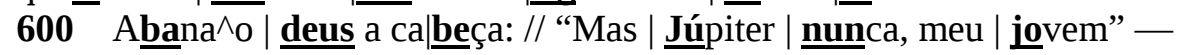
diz - "te da|rá // que as | portas de | Roma trans|ponhas, alí nem

pores o | pé. // As pla|nícies tir|renas com | morte^arra|saste,

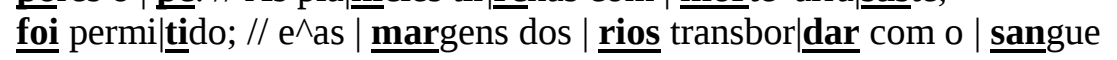

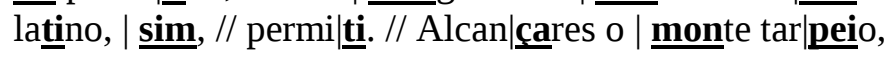

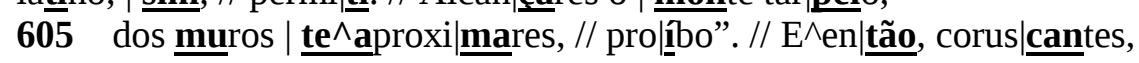

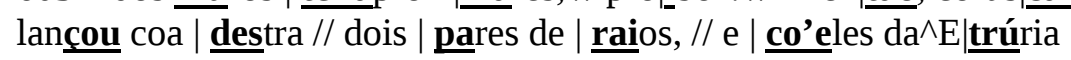

ilumi|nou-se $\mathrm{e}^{\wedge}$ a re|gião; // e nos $\mid$ ares re|volve^uma`es

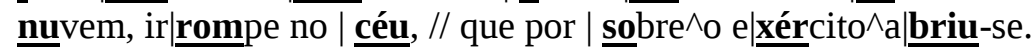

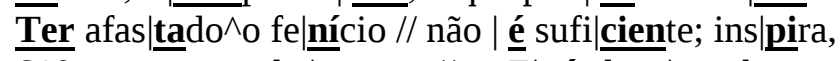

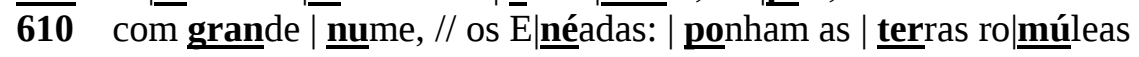

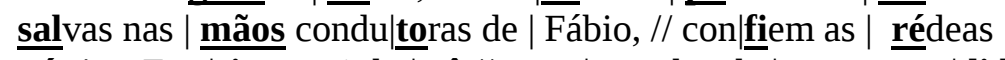

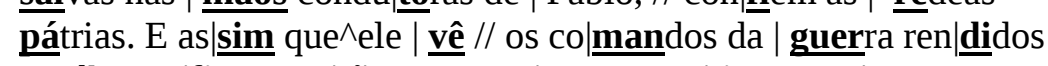

a Fábio,^a|firma^en|tão: // “O re|nome que | junto ao | povo

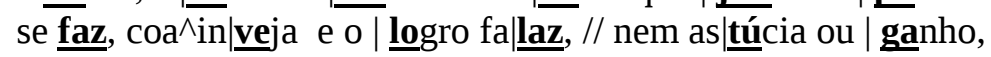

615 cobiça, | na

recebe ${ }^{\wedge}$ os $\mid$ louros na $\mid$ paz $/ /$ e su|porta das | guerras as | perdas,

$\mathrm{o}^{\wedge}$ espírito $\mid \underline{\text { calmo, }} / /$ de`en|genho i|gual // para^as $\mid$ armas $\mathrm{e}^{\wedge} \mathrm{a} \mid$ toga”.

Dos deuses fa|lou o su|premo; // re|gressa^em se|guida ${ }^{\wedge}$ às es|trelas.

Aquele, sur|preso // ja|mais por nin|guém // em suas $\mid$ armas pru|dentes,

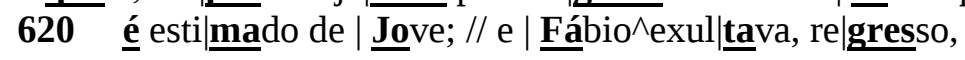

por nume|rar-se de | volta, // à | pátria | restitu|ída,

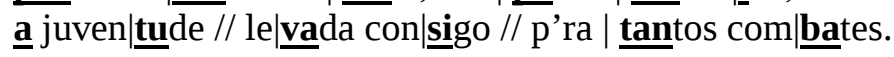

Ninguém sal|vou-se^a si | mesmo // ou | filho que|rido com | zelo

maior, ou | viu compa|nheiro // na | guerra^a san|grar com tris|teza

625 maior. A|gora $\wedge$ ele $\mid$ mesmo, // ba|nhado $\wedge$ em cru $\mid$ or ini|migo,

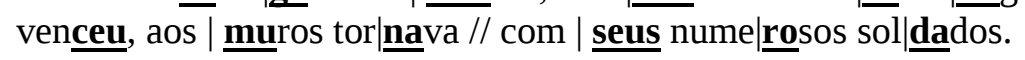

Raça de`es|tiirpe pre|clara, // ao | céu sua^o|

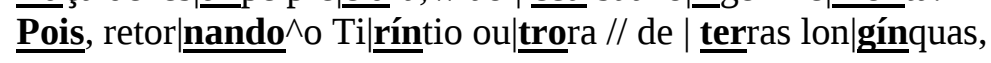




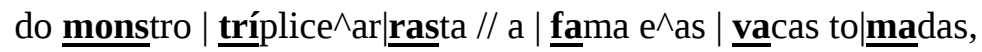
630 triunfo, $\wedge$ espe|táculo, $\mid$ onde $/ /$ re|fulgem a|gora $\wedge$ as mu|ralhas

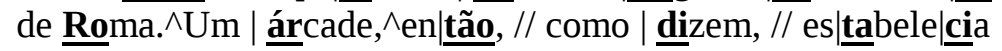
do Pala|tino as | bases // por | entre de|sertos sil|vados;

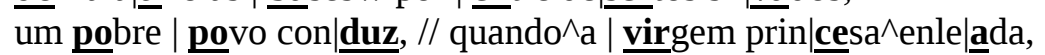

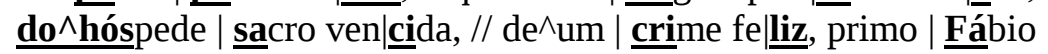

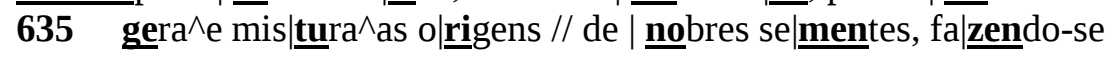

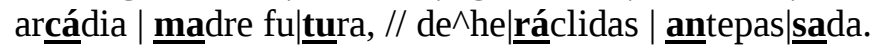

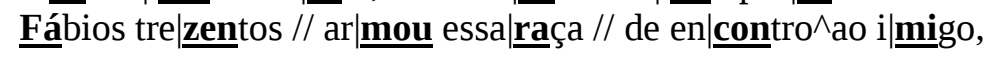
tódos salídos de^i|gual limi|ar; // os be|líssimos | feitos

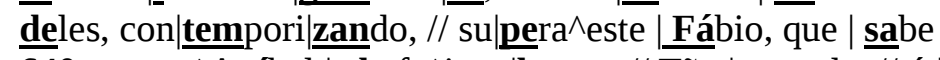
640 $\operatorname{com}^{\wedge}$ Anúbal $\mid \underline{\text { chefe }} \wedge$ igua|lar - se. // Tão | grande, // ó | púnico, | foste! Enquanto^à | guerra re|tornam // os $\mid$ sobressal|tádos la|tinos,

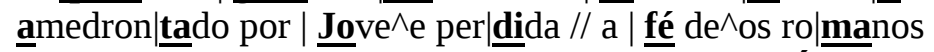

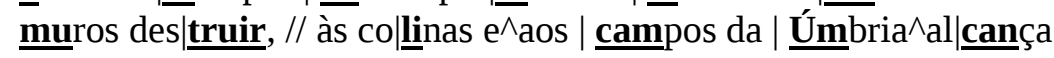
Aníbal, $\mid$ onde, $/ /$ no $\mid \underline{\text { cume}} e^{\wedge}$ ele $\mid \underline{\text { vado do }}$ dopo de^um $\mid$ monte,

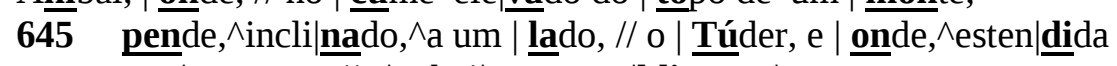
em vastos $\mid$ campos, // e| $\underline{\text { cala }}$ i|nertes ne|blinas es|pessas

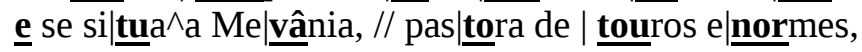
dons para | Jove; // se | lança^em se|guida // nos | campos de | $\underline{\text { Palas, }}$ Piceno, | rico ${ }^{\wedge}$ em des|pojos; // va|gando, $\wedge$ os e|xércitos $\mid$ seguem

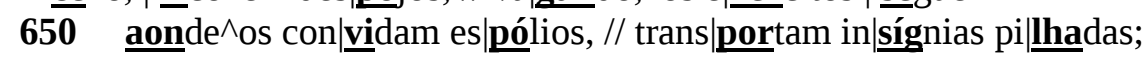

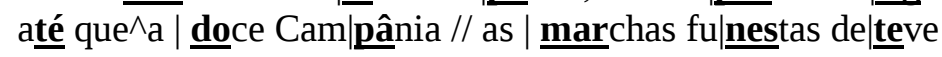

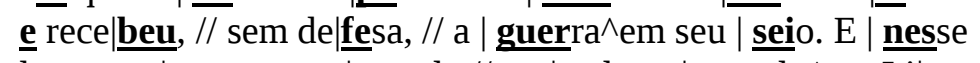

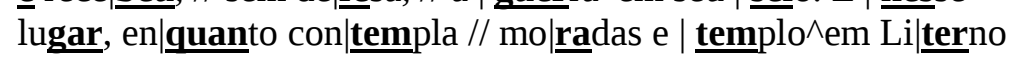

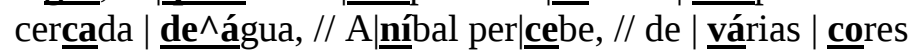
655 vivas pin|tada, // $\mathrm{a}^{\wedge} \mathrm{i} \mid \underline{\text { magem }}$ da $\mid$ guerra pri|meira, a $\mid$ cabo

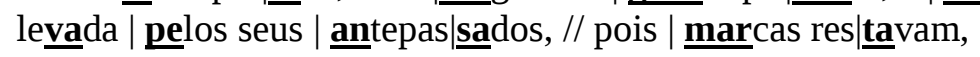

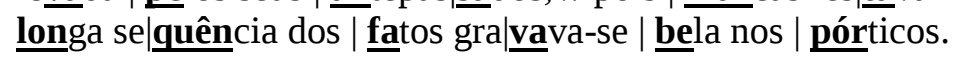
Primeiro | Régulo^à | guerra, // com | rosto fe|roz, exor|tava, guerra que, $\mid$ dado lhe $\mid \underline{\text { fosse }} / /$ os $\mid$ fados pre| $\underline{\text { ver, }}$ nega|ria. 


\section{APÊNDICE 3: Notas de comentário}

Os números em negrito referem-se aos versos (da tradução). Os comentários reúnem detalhes da construção dos versos, atinentes a questões outras que a cesura, como explicações de nomes e de escolhas da tradução.

589/590. "De acerba procela, fendida a nuvem" (At cladis acerbae discussa ceu nube) - A referência é à batalha de Trasimeno (217 a.C.), onde Aníbal obtivera a sua terceira vitória em solo italiano, após as de Ticino e de Trébia. O excerto se inicia após o retorno a Roma do filho de Régulo (cf. nota ao v. 658), Serrano, testemunha do ocorrido e personagem principal do início deste canto.

590. A expressão fessis rebus, no dativo, que Carlos Alberto Nunes traduz por “de tantos trabalhos" em En. 3.145 (Virgílio, 1981, p. 55), é equivalente a defessis rebus, utilizada por Sílio Itálico em Pun. 1.566, que Filinto Elísio (Elísio, 1817, p. 315) traduz por "no quebranto do Estado". Na nossa tradução do v. 590, "para tão grandes trabalhos".

592. Este verso é o único de terminação oxítona na nossa tradução.

596. Ausônia é, por metonímia, a Itália. O termo se aplicava, em princípio, a uma região que se estende do Sul do Lácio ao estreito de Messina, cujos habitantes se denominavam “ausônios” ou "ausões".

598. “O púnico” é Aníbal, e “tirrenos”, os seus aliados na Itália, onde o general se havia instalado desde 218 a.C., após a travessia dos Alpes. Este verso, ao lado de 617, 618 e 619, se inicia com uma anacruse (cf. Conto, 2008, p. 64; Gonçalves et al., 2011, p. 8).

602. “As planícies tirrenas” (Tyrrhenas ualles) faz referência aos territórios italianos por onde Aníbal já havia passado, obtendo vitórias e carregando consigo a devastação.

603. "As margens dos rios" (ripas fluuiorum) faz referência às duas primeiras batalhas vencidas por Aníbal, no Ticino e no Trébia, em 218 a.C. Cf. nota aos versos 589/590.

604. “O monte tarpeio” (Tarpeium collem) é um dos nomes atribuídos ao Capitolino, onde Júpiter possuía um templo, o maior de Roma.

605. O uso que faz Nunes de marcar um acento secundário no interior de uma palavra, "mecanismo só possível em palavras longas, que admitem dois acentos dentro de si e, assim, podem conter um dáctilo inteiro internalizado" (CONTO, 2008, pp. 64-65), retomei-o aqui no segundo pé, criando uma subtônica na ligação do pronome proclítico com a forma verbal polissilábica “aproximares”. Cf. o mesmo procedimento nos versos 607 e 639 e no quinto pé dos versos 621, 631 e 636.

607. Cf. nota anterior.

610. “Com grande nume” (numine magno, v. 609) - "nume” é palavra que está ligada ao mesmo radical que nuto e que significa o assentimento dado com um movimento da cabeça; por extensão, passa a significar a vontade ou o poder da divindade. Os "Enéadas" são, aqui, os próprios romanos, os descendentes dos companheiros de Eneias.

611. Quinto Fábio Máximo, o Contemporizador (Cunctator), ficou assim conhecido por sua estratégia de combate a Aníbal durante a Segunda Guerra Púnica, na sua ditadura de 217 a.C. A tática consistia em atrasar o combate em cam- 
po aberto e fazer, assim, com que as forças cartaginesas perdessem vigor. Os versos seguintes farão um elogio (a encerrar-se no v. 640) dessa mesma personagem.

617, 618 e 619. Versos iniciados com anacruse, como o 598 (cf. CONTO, 2008, p. 64; GONÇALVES et al., 2011, p. 8).

620-6. A caracterização de Fábio presente nestes versos, além de reiterar a estima de Júpiter pelo general, já apresentada nos versos anteriores (cf., a este respeito, a nota ao v. 627), destaca o seu papel de defensor, em detrimento da sua capacidade de ataque. Essa tendência, descrita por Plutarco na Vida de Marcelo (9.7) com a expressão “o escudo do Estado”, tomada ao historiador e filósofo Posidônio de Apameia, é estudada como um modelo de heroísmo que se destaca nas Púnicas em FUCECCHI, 2010, pp. 219-230. Sobre o zelo de Fábio, que protege seus soldados com mais cuidado que um pai a seu filho, cf. BERNSTEIN, 2010, sobretudo p. 382.

621. Cf. nota ao verso 605.

627. A "raça de estirpe preclara" (stirpe genus clarum) de Fábio tem origem na figura de Hércules, filho de Júpiter e Alcmena, realizador dos doze trabalhos, divinizado após a sua morte, paradigma recorrente de heroísmo nas Púnicas (cf. ASSO, 2010, pp. 179-192). Os versos seguintes (628-637) descreverão a lenda da origem divina da gens Fabia.

628. O "Tiríntio" (Tirynthius) é Hércules: em algumas versões, o herói é dado como nascido em Tirinto, cidade fortificada no topo de uma colina, na Argólida. Um dos reis dessa cidade havia sido Alceu, avô materno de Hércules, de quem o herói recebe outra alcunha, a de "Alcida".

629. Habitante da ilha de Eritia, o "monstro tríplice” (triplicis monstri) é Gerião, gigante de três cabeças e cujo corpo era também triplicado até a cintura; constituiu um dos doze trabalhos de Hércules a tomada dos rebanhos de bois desse monstro.

631. Para a tonicidade do quinto pé, cf. nota ao verso 605. "Um árcade” (Arcadius) é Evandro, exilado que, tendo recebido a autorização de Fauno, rei dos indígenas da terra a que chegara, fundou uma cidade no topo do Palatino, a que deu o nome de Palanteu. Nesse mesmo local, Evandro recebeu Hércules e o purificou do assassínio de Caco; reconhecendo o Tirinto como filho de divindades, Evandro ergueu-lhe um altar, conhecido como Ara Maxima. Foi aí também, mais tarde, que Rômulo fundou a cidade de Roma. Evandro é também personagem no canto VIII da Eneida de Virgílio.

633-4. “A virgem princesa enleada” (regia uirgo... uicta) é Vidumna, filha de Evandro.

635. Este verso e o 657 são os únicos de terminação proparoxítona em nossa tradução.

636. Para a tonicidade do quinto pé, cf. nota ao verso 605.

637. Com "Fábios trezentos" (ter centum... Fabios), Sílio renova a referência à lenda de que, durante a guerra contra os veios (477 a.C.), um exército de 306 homens, formado da gens Fabia,teria perecido às margens do rio Crêmera, na Etrúria, restando um só sobrevivente (cf. Tito Lívio, 2.48-50). A mesma lenda já havia sido mencionada por Sílio Itálico em 2.3-6 e será retomada, na fala de Cílnio a Aníbal, em 7.34-68.

639. Para a tonicidade do segundo pé, cf. nota ao verso 605. "Contemporizando” (cunctando), porque a estratégia militar de Fábio foi adiar as batalhas em 
campo aberto que vinham oferecendo vitórias a Aníbal; dessa forma, o general cartaginês foi-se vendo isolado do contato com seus aliados e privado dos sucessos que mantinham a motivação do seu exército.

641. Para a tonicidade do quarto pé, cf. nota ao verso 605.

643-52. Estes versos descrevem a marcha de Aníbal em território italiano, a partir de 218 a.C. , após haver atravessado os Alpes. O Túder e a Mevânia são cidades da Úmbria.

646-8. Miniconi e Devallet (SILIUS ITALICUS, 1979, p. 161, n. 4) explicam que a região de pastagem onde se situa a Mevânia era banhada pelo Clitumno, rio que se acreditava que tornasse a pelagem dos touros branca, exigida para os sacrifícios solenes.

648-9. O Piceno é chamado "campos de Palas” (Palladios... agros) por ser rico em oliveiras, cujo cultivo foi ensinado aos mortais pela deusa Palas Atena (SILIUS ITALICUS, 1981, p. 155, n. 2).

655. Com a tradução "imagem" que se apresenta em vez de monumenta do original, concordamos com a interpretação de Miniconi e Devallet (SILIUS ITALICUS, 1981, p. 57a) e de Álvarez (2005, p. 308), ressaltando uaria... pictura (ao pé da letra, “em pintura variada”, vv. 654-5). A palavra latina, no entanto, marca a noção de lembrança, de rememoração e de comemoração que tais figuras representam, visto que ilustram a "guerra primeira", a Primeira Guerra Púnica (264-241 a.C.), cuja vitória sobre Amílcar Barca, pai de Aníbal, implicou para os romanos, entre ouros ganhos, a posse da Sicília e da Sardenha e o início de uma potestade marítima. Sobre o olhar de Aníbal, cf. COWAN, 2005, pp. 349351; sobre a écfrase dessas imagens nos versos seguintes, cf. HARRISON, 2009, pp. 287-289.

656. Para a tonicidade do terceiro pé, cf. nota ao verso 605.

657. Este verso e o 635 (cf. nota) são os únicos de terminação proparoxítona na nossa tradução.

658. Marco Atílio Régulo (morto ca. 250 a.C.), segundo dos três nomes de maior destaque político da gens Atilia, foi cônsul em 267 a.C. e novamente em 256 a.C. Durante seu segundo consulado, ao lado de Lúcio Mânlio Vulso Longo, esteve à frente dos combates contra a potência cartaginesa, que venceu em batalha marinha no Cabo de Ecnomo e, em seguida, tendo passado às terras africanas, nos montes de Adis. Esse ciclo de vitórias romanas se encerrou com a tomada da direção dos exércitos cartagineses por um general grego, Xantipo, que impôs grande derrota aos romanos na batalha de Bagradas. Marco Atílio Régulo, após cativeiro de cinco anos, foi enviado a Roma em 250 a.C., para que convencesse os romanos à paz e à troca de prisioneiros. Opôs-se às propostas de Cartago diante do Senado e retornou a África, onde foi supliciado até a morte. Diversas lendas giram em torno da personagem, e algumas são retomadas nas Púnicas. Neste mesmo canto, nos vv. 62-551, muitas são narradas por Maro, antigo soldado de Régulo.

Everton Natividade

everton.natividade@ufpe.br

Prof. Mestre., Universidade Federal de Pernambuco 


\section{Referências bibliográficas}

Asso, Paolo. Hercules as a paradigm of Roman heroism. In: Antony Augoustakis (ed.). Brill's Companion to Silius Italicus. Leiden and Boston: Brill, 2010, pp. 179-192.

Bernstein, Neil W. Family and state in the Punica. In: Antony Augoustakis (ed.). Brill's Companion to Silius Italicus. Leiden and Boston: Brill, 2010, pp. 377-397.

Chociay, Rogério. Teoria do verso. São Paulo: McGraw-Hill do Brasil, 1974. 212pp.

ConTo, Luana de. Carlos Alberto Nunes, tradutor dos clássicos. Anais da XXIII Semana de Estudos Clássicos, Araraquara, pp. 60-67, 2008. Disponível online em

http://portal.fclar.unesp.br/ec/BANCO\%20DE\%20DADOS/XXIII\%20S EC/TEXTOS/ARTIGOS\%20PDF/conto.pdf > . Acessado em 23/2/2013.

CowAN, Robert. Virtual Epic: counterfactuals, sideshadowing, and the poetics of contingency in the Punica. In: Antony Augoustakis (ed.). Brill's Companion to Silius Italicus. Leiden and Boston: Brill, 2010, pp. 323351.

CRUSIUS, Federico. Iniciación en la métrica latina. Versión y adaptación de Ángeles Roda. Barcelona: Bosch Casa Editorial, 1951. 190pp.

Elysio, Filinto. Obras completas de Filinto Elysio. Tomo II. Paris: A. Bobée, 1817. 464pp.

FuCECCHI, Marco. The shield and the sword: Q. fabius Maximus and M. Claudius Marcellus as models of heroism in Silius' Punica. In: Antony Augoustakis (ed.). Brill's Companion to Silius Italicus. Leiden and Boston: Brill, 2010, pp. 219-239.

GonÇALVES, Rodrigo Tadeu et alii. Uma tradução coletiva das Metamorfoses 10.1-297 com versos hexamétricos de Carlos Alberto Nunes. Scientia traductionis, Florianópolis, No. 10, pp. 110-132, 2011. Disponível online em <http://dx.doi.org/10.5007/1980-4237.2011n10p110>. Acessado em 23/2/2013.

HARRISON, Stephen J. Picturing the future again: proleptic ekphrasis in Silius' Punica. In: Antony Augoustakis (ed.). Brill's Companion to Silius Italicus. Leiden and Boston: Brill, 2010, pp. 279-292.

Homero. Ilíada. Tradução dos versos e introdução de Carlos Alberto Nunes. Rio de Janeiro: Ediouro, 2009a. 576pp.

. Ilíada. Tradução dos versos e introdução de Carlos Alberto Nunes. São Paulo: Hedra, 2011a. 506pp.

. Ilíada. Tradução dos versos e introdução de Carlos Alberto Nunes. Rio de Janeiro: Nova Fronteira, 2011b. 608pp.

. Odisseia. Tradução dos versos e introdução de Carlos Alberto Nunes. Rio de Janeiro: Ediouro, 2009b. 432pp.

. Odisseia. Tradução dos versos e introdução de Carlos Alberto Nunes. São Paulo: Hedra, 2011c. 400pp.

. Odisseia. Tradução dos versos e introdução de Carlos Alberto Nunes.

Rio de Janeiro: Nova Fronteira, 2011d. 477pp. 
Nunes, Carlos Alberto. Ensaio sobre a poesia épica. In: . Os Brasileidas. Epopeia nacional em nove cantos e um epílogo. São Paulo: Edições Melhoramentos, 1962. pp. 5-59.

Silio ITÁliCo. La Guerra Púnica. Edición de Joaquín Villalba Álvarez. Madrid: Clásica, 2005. 640pp.

SiLIUS ITALICUS. La Guerre Punique. Tome I. Livres I-IV. Texte établi et traduit par Pierre Miniconi et Georges Devallet. Paris: Société d’Éditions “Les Belles Lettres”, 1979. 166pp.

. La Guerre Punique. Tome II. Livres V-VIII. Texte établi et traduit par José Volpilhac (Livre V), Pierre Miniconi et Georges Devallet (Livres VI-VIII). Paris: Société d’Éditions “Les Belles Lettres”, 1981. 192pp.

VIRGílio. Eneida. Tradução portuguesa de Carlos Alberto Nunes no metro original. São Paulo: A Montanha Edições, 1981. 279pp. 